\title{
TEORIAS ATUAIS DA PENA E O PROJETO DE REFORMA PENAL BRASILEIRO
}

Ela Wiecko Volkmer de Castilho

\section{TENDÊNCIAS BÁSICAS}

As investigações teóricas sobre a natureza, o sentido, os limites, as finalidades, as funções da pena estão longe de ter chegado a conclusões pacíficas, acabadas.

Em especial, a controvérsia sobre o sentido e a função da pena não cessou. Isso, por uma razão simples. A teoria da pena se liga à concepção de Estado. Sendo esta uma concepção que no curso da história vai sendo superada, transformada, é natural que, também, a teoria da pena esteja em contínuo questionamento face às mutantes circunstâncias sócio-político-econômicas.

Apesar disso, é interessante notar que, em toda discussão subjaz o confronto entre duas tendências básicas, a da retribuição e a do utilitarismo.

Podemos perceber esse fato em um texto antigo, extraído da obra A Guerra do Poloponeso, de Tucídides. Numa passagem em que os atenienses discutem a atitude que devem adotar frente à revolta dos mitilênios, habitantes da ilha de Lesbos, Cleon, o mais violento e mais poderoso homem de Atenas, reclama a morte dos mitilênios e lhes nega toda mercê, porque, afirma, sua ofensa não foi involuntária senão deliberada e com malícia:

“Direi numa palavra: se aceitardes meus conselhos, fareis não somente justiça aos mitilênios, mas também, e ao mesmo tempo, o que nos convém; se decidirdes de outra maneira, não obtereis a sua gratidão mas, ao contrário, estareis decretando a vossa própria condenação, pois se este povo tinha o direito de rebelar-se não poderíeis exercer o império. Se, porém, com ou sem razão estais resolvidos a exercê-lo, então deveis punir este povo mesmo contra a equidade, ape- 
nas por vosso interesse; ou devereis desistir do império e viver sem riscos como homens virtuosos".

E aduz, quase ao finalizar seu discurso: ". . . castigai-os como merecem; isto servirá de advertência clara aos outros aliados no sentido de que os rebelados serão punidos como a morte".

Depois dele Diodotos, filho de Eucrates, que na assembléia anterior havia sido o principal orador contra a condenação dos mitilênios à morte, subiu também à tribuna e disse o seguinte:

“. . . considerando sensatamente as coisas, não se trata de sua culpa (dos mitilênios), mas do melhor partido a tomar em relação a nós mesmos. Posso demonstrar que eles são plenamente culpados sem todavia reclamar a sua morte, se isso não nos traz vantagens; da mesma forma, só os perdoaria na medida em que o bem da cidade o exigisse. Considero nosso dever deliberar mais sobre o futuro que sobre o presente. Cleon afirma que a pena máxima será útil no porvir, porque diminuirá as defecções, mas a consideração de nossos interesses futuros me conduz a uma conclusão contrária. Não vos deixeis levar pela capciosidade de seus argumentos para repelir o que há de útil nos meus. Seu discurso, influenciado por vossa cólera contra os mitilênios, pode atrair-vos; não nos cabe agora, todavia, processá-los nem pesar a justeza de sua conduta, mas deliberar sobre eles para determinar a conduta que os tornará mais úteis a nós." 1

Cleon representa o retributivismo, pois essa tendência justifica a pena em razões de justiça. Se o autor de uma ofensa causou um dano, merece ser castigado.

Os mitilênios devem ser castigados porque são culpados da ofensa, é justo que se os castigue.

Diodotos representa o utilitarismo, tendência que se vê na utilidade ou na oportunidade a justificativa da pena. Nesse enfoque algurns utilitaristas pensam primordialmente no efeito intimidativo geral e particular do castigo enquanto outros valorizam mais a reforma do ofensor.

Diodotos afasta as razões de justiça, pondera a utilidade futura da condenação, a oportunidade pol ítica.

Interessante observar ainda que Cleon projeta seu raciocínio para um fato do passado, enquanto Diodotos o faz para o futuro.

Apesar das diferenças, uma análise acurada das argumentações revela aqui e ali tentativas de conciliação com a respectiva tese rival.

Por exemplo, quando Cleon aduz: ". ... castigai-os como merecem, isso servirá de advertência clara . . ." há uma concessão à tese utilitarista. De seu lado, Diodotos não descarta por completo a culpabilidade dos mitilênios e as razões de justiça.

Tradicionalmente essas duas tendências são vistas como antagônicas.

1 TUCIDIDES, História da Guerra do Poloponeso. Trad. Mário da Gama Kury, Brasília, Editora Universidade de Brasília, 1982, pp. 149-151. 
ALF ROSS, comentando o fato, observa que decorre de um equívoco, de uma confusão sobre diferentes categorias de problemas. A seu ver, o utilitarismo responde à questão do fim da pena (para que se pune), enquanto o retributivismo liga-se à questão do fundamento da pena (por que se pune). Não há incompatibilidade lógica entre as idéias de retribuição e de prevenção. ${ }^{2}$

A colocação procede. No entanto, é interessante observar, e já observei pessoalmente em debates em sala de aula suscitados em torno da indagação Por que Punir?, que sempre um grupo finda por transmudar na resposta o "por" pelo "para", ou seja, coloca o fim da pena como seu próprio fundamento.

Sob outro ângulo, já no terreno prático, ocorre o inverso: as instituições penitenciárias que se propõem a realizar as finalidades preventivas apresentam uma tendência a sublinhar a natureza punitiva da pena.

Essas constatações me levam a concluir que a lógica é insuficiente para explicar a pena.

Voltando às tendências antes expostas constata-se que, historicamente, desenvolveu-se primeiro a concepção retributiva, cujo conteúdo essencial foi expressado com maestria por KANT e HEGEL. Nessa concepção a pena existe porque é necessária à realização da Justiça. A pena cumpre um papel restaurador da ordem violada.

A partir do século XVIII foi sobrepujada pela concepção utilitarista, que abriga duas correntes principais. A primeira sublinha a finalidade da prevenção geral. Vê na pena um meio de advertência à coletividade para que se abstenha de delinquir. A segunda sublinha a finalidade da prevenção especial. Vê na pena um meio de atuação sobre o delinquente individualmente para corrigir sua tendência anti-social ou impedir a continuidade delitiva mediante a segregação.

Igualmente é verificável uma procedência da primeira corrente sobre a segunda.

Contudo, ressalvo que as afirmações sobre a procedência de uma ou outra concepção ou corrente devem ser entendidas com reserva, no sentido apenas de uma prevalência. Note-se, por exemplo, que os contornos básicos da concepção utilitária são encontrados na obra de Platão.

$\mathrm{Na}$ atualidade os estudiosos se inclinam por soluções integradoras, criando fórmulas conciliatórias ou então enfocando a questão sob novos pontos de vista.

Veremos a seguir alguns exemplos das teorias atuais sobre a pena.

TEORIAS ATUAIS

As posições ecléticas mais simples são aquelas que a partir de VON

2 ROSS, Alf. On Guilt, Responsibility and Punishment. London, Steves \& Sons Limited, 1975. p. 60-61. 
LISZT estabeleceram o sistema do duplo binário no direito penal, entre penas e medidas de segurança. As primeiras de natureza retributiva, fundadas na culpabilidade, as segundas de natureza preventiva, fundadas na periculosidade. Esse critério teve enorme influência na legislação, inclusive na nossa, mas se revelou insatisfatório na prática, diante da incompatibilidade entre a idéia de castigo e de ressocialização.

Outra fórmula mista é a de MERKEL e JAKOBS que procura combinar a retribuição com a prevenção geral, assinalando que a pena é um mal e uma resposta à ação realizada com o fim de fortalecer os preceitos e as obrigações violadas. A prevenção geral não tem sentido intimidatório, mas de exercício de fidelidade ao direito. ${ }^{3}$

Já o Projeto Alternativo Alemão, de 1966, combina a prevenção geral com a especial, reforçando o critério preventivo-geral. Nessa conceção o direito penal serve para manter a ordem jurídica necessária aos homens e há que conformar as sanções de tal modo que permitam, se necessário e possível, a reinserção do condenado ria comunidade.

WINFRIED HASSEMER opta por uma revisão da concepção da prevenção geral. Abandona a prevenção geral intimidatória, cuja eficácia até hoje carece de comprovação e sustenta uma prevenção geral que visa a estabilização da consciência do direito, muito semelhante à preconizada por MERKEL, JAKOBS e também CARRARA. ${ }^{4}$

BERNHARD HAFFKE, na mesma linha, concebe a pena e o direito penal como um controle social-jurídico nacional e esclarecido que leva em conta as debilidades do delinquente e o trata humanamente. ${ }^{5}$

ENRIQUE BACIGALUPO abandona a retribuição e desenvolve suas idéias no campo da prevenção, sustentando que a intervenção preventivo-especial do Estado só se justifica frente a um agente que não seja capaz de reagir inibindo-se ante a ameaça da pena e que, ao mesmo tempo, tenha consciência da punibilidade. Preocupa-se em traçar um sistema de prevenção especial orientado democraticamente e nele tem importância a distinção entre as categorias da culpabilidade e da punibilidade, correspondentes à "ação merecedora de pena" (Strafwürdigkeit) e "ação que requer punibilidade" (Strafbedürftigkeit). ${ }^{6}$

CLAUS ROXIN expõe uma teoria nominada de unificadora dialética, em que diferencia os distintos momentos em que atua a pena, pretendendo evitar o exagero unilateral e dirigir os diversos fins da pena para vias socialmente construtivas, estabelecendo um equil íbrio dos princ ípios através de restrições recíprocas.

Assim, vê em primeiro lugar o momento da cominação penal, na qual ressalta a finalidade preventivo-geral. No seu conceito de prevenção geral os elementos de ameaça e intimidação se vêem limitados pelos princípios da subsidiariedade e da culpabilidade. Isto significa que a

3 apud RAMIREZ, Juan Bustos. Bases Críticas de un Nuevo Derecho Penal Bogotá,:Temis, p. 172.

4 id., p. 173

5 id., p. 173

6 BACIGALUPO, Enrique. Delito y Punibilidad. Madrid, Civitas, 1983, p. 
pena só deve ser prevista como retribuição quanto haja necessidade social de salvaguarda da ordem jurídica na consciência da comunidade.

A idéia de retribuição evidentemente está presente na cominação penal, ROXIN a reconhece, mas não the dá realce.

Após, examina o momento de imposição concreta da pena pela atividade judicial. Nesse momento a pena serve à proteção subsidiária e preventiva, tanto geral como individual, de bens jurídicos e prestações estatais, mediante um procedimento que salvaguarde a autonomia da personalidade e limitado pela culpabilidade.

Finalmente, examina o terceiro momento, da execução da pena, que só se justifica na finalidade de reincorporação do delinquente à comunidade, isto é, uma finalidade preventiva especial.

A colocação de ROXIN é na verdade essencialmente preventiva porque o momento retributivo fica totalmente esvaziado de seu conteúdo clássico e é apenas uma manifestação da justiça, no sentido do limite imposto pela culpabilidade à prevenção.

$\mathrm{Na}$ síntese do processo dialético o momento predominante é o preventivo especial. A pena só se justifica se persegue a reincorporação do delinquente à comunidade. Só é legítima uma execução ressocializadora.

O fantasma da arbitrariedade sempre presente na concepção preventiva especial é afastado, ao ver de ROXIN, pelo condicionamento recíproco dos três momentos e sobretudo porque a pena encontra limite no princípio da culpabilidade. ${ }^{7}$

ROLF-PETER CALLIESS investiga as funções da pena a partir do sistema penal. A pena faz parte de um sistema dialogal entre o eu, o outro e um terceiro. A pena tem a função de regular esta interação, não como retribuição ou como tratamento, mas como possibilidade de participação social. No fundo protege a possibilidade de participação social, a confiança no sistema, apesar da infração, e ao mesmo tempo cria possibilidade de participação, que seria o sentido da ressocialização. ${ }^{8}$

É uma visão poética, bastante vaga e imprecisa, mas que desvenda aspectos que devem ser melhor investigados porque implica em uma postura essencialmente democrática.

SANTIAGO MIR PUIG preocupa-se com a função da pena e seu ponto de partida metodológico é a função do Estado. Como a pena é um dos instrumentos com que o Estado conta para impor suas normas jurídicas, a função da pena depende daquela assinalada ao Estado.

No Estado social democrático de Direito, a pena deve cumprir uma missão política de regulação ativa da vida social, que assegure seu funcionamento satisfatório, mediante a proteção dos bens dos cidadãos. Isto supõe a necessidade de conferir à pena a função de prevenção dos fatos que atentem a estes bens e não se basear em uma hipotética necessidade ético-jurídica de não deixar sem resposta, sem retribuição, a in-

7 ROXIN, Claus. Problemas Básicos del Derecho Penal. Trad. de Diego-Manoel Luzon Peña, Madrid, Reus, 1976. p. 31-34.

8 apud RAMIREZ, Juan Bustos, ob. cit., p. 177. 
fração da ordem jurídica. Para que o Estado social democrático não se converta em autoritário, deverá respeitar uma série de limites que garantam que a prevenção se exercerá em benefício e sob controle de todos os cidadãos. (proteção de bens jurídicos e proporcionalidade; princípio da legalidade; aceitação das convicç̃̃es da maioria, respeitando a minoria).

Adotando francamente a função preventiva da pena distancia-se de ROXIN e do Projeto Alternativo alemão ao destacar dentro da prevenção o papel preponderante da prevenção geral. A norma penal deve criar expectativas sociais que motivem a coletividade a agir contra o cometimento de delitos. ${ }^{9}$

JUAN BUSTOS RAMIREZ, distingue dois aspectos diferentes na pena. O primeiro refere-se ao que é a pena, o segundo à imposição da pena.

Quanto ao primeiro aspecto pena é autoconstatação ideológica do Estado, i. é, através dela o Estado demonstra sua existência frente a todos os cidadãos e lembra que o sistema vige. A pena não tem fins, apenas funções. Assim, exerce a função de proteção dos bens jurídicos que o sistema valorou de modo especial.

Ela só pode autoconstatar e proteger mediante sua coação, mas não pode pretender motivar, pois isso ultrapassa sua possibilidade de legitimação em um Estado social e democrático de direito.

O outro aspecto é o da imposição, dirigido ao delinquente em particular e deve ter como base a consideração da dignidade da pessoa humana. Nessa perspectiva BUSTOS RAMÍREZ condena a ressocialização ou reeducação, pois isso sempre significa adaptar a uma determinada socialização ou reeducação, que é a considerada verdadeira pelo Estado, mas que não o é necessariamente.

Reconhecer a dignidade do homem supõe antes de tudo evitar a imposição da pena através de uma ação preventiva do Estado, oferecendo condições favoráveis para que não se cometam delitos e que, ao mesmo tempo, as penas fiquem limitadas ao menor número de hipóteses, apenas as indispensáveis à necessidade de auto constatação. ${ }^{10}$

\section{O PROJETO DE REFORMA PENAL}

No ano de 1980, o Sr. Ministro de Estado da Justiça designou três comissões de juristas incumbidas de estudar a legislação penal e de conceber as reformas necessárias às exigências atuais da sociedade brasileira.

Do dedicado trabalho dos componentes dessas comissões resultaram três anteprojetos: o da Parte Geral do Código Penal, o do Código

9 MIR PUIG, Santiago. Funcion de la Pena y Teoria del Delito en el Estado Social y Democrático de Derecho. Barcelone, Bosch Casa Editorial, S. A. $2^{\text {a }}$. ed. rev., 1982, p. 41-48.

10 RAMÍREZ, Juan Bustos, ob. cit., p. 179-185. 
de Processo Penal e o da Lei de Execução Penal, publicados no Diário Oficial da União em 1981.

Esses anteprojetos foram divulgados e debatidos em simpósios, painéis e congressos, merecendo críticas e sugestões. Foram então instituídas novas comissões que revisaram os anteprojetos e neles introduziram as alterações julgadas convenientes, apresentando novos textos, encaminhados pelo Presidente João Figueiredo como projetos de lei à deliberação do Congresso Nacional em 29 de junho de 1983. Os projetos, relativos à Parte Geral do Código Penal e à Lei de Execução Penal foram aprovados pelo plenário da Câmara dos Deputados e pelo Senado Federal, aguardando agora a sanção presidencial.

$\mathrm{Na}$ passagem pela Câmara os textos sofreram poucas emendas, as quais, no entender de FRANCISCO DE ASSIS TOLEDO, Coordenador do Projeto da Reforma não prejudicaram a estrutura básica daquele Projeto. ${ }^{11}$

Meu objetivo é analisar os textos dos anteprojetos e dos projetos, que se referem à alteração do Código Penal e à criação da Lei de Execução Penal para demonstrar a concepção de pena subjacente. Servirão de subsídio para a análise manifestações publicadas por integrantes das comissões redatora e revisora.

$\mathrm{O}$ art. 59 do anteprojeto sob a rubrica "fixação da pena" está redigido nos seguintes termos:

“O juiz, atendendo os antecedentes, à conduta social e à personalidade do agente, às circunstâncias e aos motivos, à intensidade do dolo ou ao grau da culpa e conseqüências do crime, bem como ao comportamento da vítima, estabelecerá:

I - as penas aplicáveis dentre as cominadas, conforme seja necessário e suficiente para reprovação e prevenção do crime;

Por sua vez o art. 10. do anteprojeto da Lei de Execução Penal dispõe que:

"A lei de execução regula o cumprimento da pena e da medida de segurança, a fim de que se alcancem a reprovação e a prevenção do crime.

Parágrafo único. Constitui objetivo mediato da execução penal a educação e a assistência que, no futuro, facilitem ao condenado harmônica convivência em sociedade".

Cabe anotar o mandamento expresso no art. $4^{\circ}$.:

“ $N a$ aplicação das normas relativas à execução da pena e da

11 Palestra na inauguração do $3^{0}$. Seminário de Estudos do Ministério Público do Paraná, Curitiba, 24.05.84. 
medida de segurança, o Estado deverá recorrer à cooperação da comunidade".

Por seu lado, o art. 59 do projeto, redigido como segue, mostra algumas alterações:

"O juiz, atendendo à culpabilidade, aos antecedentes, à conduta social, à personalidade do agente, às circunstâncias e consequências do crime, bem como ao comportamento da vítima, estabelecerá, conforme seja necessário o suficiente para reprovação e prevenção do crime:

I - as penas aplicáveis dentre as cominadas".

$\mathrm{O}$ art. ${ }^{10}$. do projeto de Lei de Execução Penal também apresenta alteração como segue:

"A execução penal tem por objetivo efetivar as disposições de sentença ou decisão criminal e proporcionar condições para a harmônica integração social do condenado e do internado"'.

$\mathrm{O}$ art. $4^{\circ}$. dispõe que:

“O Estado deverá recorrer à cooperação da comunidade nas atividades de execução da pena e da medida de segurança".

Embora nos dois textos transpareça a mesma concepção básica da pena, percebe-se que houve alterações e o exame delas nos permite melhor determinar as influências doutrinárias.

$\mathrm{Na}$ análise, para simplificar a comunicação, referir-me-ei ao texto do anteprojeto como texto 1 e ao do projeto como texto 2 .

Ao explicitar no art. 59 (textos 1 e 2) que o juiz estabelecerá a pena "para reprovação e prevenção do crime" o legislador inequivocamente optou por uma concepção eclética da pena, em que esta possui a natureza retributiva e uma função preventiva. Não há especificação quanto ao tipo de prevenção, se geral ou especial, o que sugere um conceito amplo de prevenção de modo a abranger a intimidação geral da coletividade e a particular do indivíduo delinquente.

Sob outro ângulo ambos os textos incorporam um dos postulados da teoria do fim da pena de VON LISZT, segundo a qual não se pode castigar por falta de necessidade - ou seja, quando outras medidas de política social ou as próprias prestações voluntárias do delinquente garantem uma suficiente proteção dos bens jurídicos; ou por falta de idoneidade, quando a pena seja político criminalmente inoperante ou até nociva (princípios da subsidiariedade e de efetividade).

Esses postulados estarão explícitos na expressão "conforme seja necessário e suficiente para reprovação e prevenção do crime" e implí- 
citos no novo sistema de penas que enfatiza as sanções pecuniárias e restritivas de direito e que possibilita ao juiz optar pela mais conveniente em cada caso. Esses postulados também deverão orientar o legislador na reformulação em curso da parte especial do Código no sentido da descriminalização de certas condutas.

A inserção explícita dos princípios da subsidiariedade e da efetividade faz sobressair na concepção eclética adotada a finalidade preventiva.

Já havia alinhavado essa conclusão quando tive ocasião de ouvir do próprio ASSIS TOLEDO a firmação de que na estratégia da reforma penal a prevenção é o objeto mais importante. ${ }^{12}$

Ressalta no texto 2 a substituição da expressão "intensidade do dolo ou ao grau da culpa" por "culpabilidade".

A Exposição de Motivos, subscrita pelo Ministro Ibrahim Abi-Ackel, explica que "preferiu o Projeto a expressão "culpabilidade" em lugar de "intensidade de dolo ou grau de culpa", visto que graduável é a censura, cujo índice, maior ou menor, incide na quantidade da pena".

Então, o juiz, atento ao grau de culpabilidade (= reprovação social), entre outros critérios, estabelecerá em concreto a pena aplicável dentre as cominadas e a quantidade de pena aplicável, dentre os limites previstos.

A culpabilidade passa a ser, sem dúvida, um critério para a imposição da pena em concreto, afastando o critério da periculosidade, este subsistente para os inimputáveis, aos quais não se aplica pena, mas medida de segurança.

A extinção da medida de segurança para o imputável bem como a regra do art. 19 do Projeto que altera a parte geral do Código, pela qual, no resultado que agrava especialmente a pena, o agente só responde quando o houver causado menos culposamente, são louváveis e representam a consagração das críticas que tem sido feitas pelos estudiosos ao Cód. Penal de 1940.

Cabe indagar, porém, se a fórmula adotada se afina com a doutrina de ROXIN, segundo a qual a culpabilidade, inadequada para fundamentar o direito de punir, deve servir para limitá-lo.

Diz ele que há uma diferença fundamental entre utilizar a idéia de culpabilidade para entregar o indivíduo à mercê do poder do Estado $\mathrm{e}$ para preservá-lo do abuso desse poder e que essa questão é mais importante para o Direito Penal que aquela da existência de culpabilidade. Sustenta que a culpabilidade só deve servir como princípio limitativo da pena porque a dignidade humana proclamada pela Lei Fundamental alemã é um direito anterior ao Estado. ${ }^{13}$

12 $3^{\circ}$. Seminário de Estudos do Ministério Público do Paraná, Curitiba, 24.5.84.

13 ROXIN, Claus. Problemas básicos del derecho penal. Trad. de Diego - Manuel Luzón Peña. Madrid, Reus, 1976, p. 28. 
Nesse sentido anota que:

Ciertamente hay que tomarse en serio la idea de que están absolutamente prohibidas las pena inadecuadas a la culpabilidad. Por conseguiente es inadmisible, para citar un ejemplo actual, dictar contra una persona intelectualmente limitada que, inducida por personas de edad, pinta cruces gamadas en las paredes, una pena dura y que sobrepase ampliamente su culpabilidad comparativamente escasa, sólo para que otros se abstengam de esa fechoría. Como tampoco se puede estatuir en los delitos de tráfico, por muy importante que sea la contención de esos delitos, penas e ejemplares que no estén cubiertas por el grado de culpabilidad personal. En una palabra: el fin de prevención general de la punición sólo se puede perseguir en el março de la culpabilidade individual. Si se vá más allá y por tanto se hace expiar el autor por las presuntas tendencias criminales de otros, se atenta en realidad contra la dignidade humana. Pues la eficacia protectora de este concepto consiste precisamente en que el particular es para el orden jurídico la medida de todas las cosas, en cuanto que tiene que responder con su persona sólo por aquello de lo que conceptualmente esa persona es culpable. Pero respecto al futuro comportamiento de terceros, nada puede aquél; si se le castiga por ello, dicho castigo, por muy duro que suente la comparación, será de la misma categoria que la responsabilidad por el azar o la responsabilidad por la estirpe. ${ }^{14}$

ROXIN critica o Projeto de Código Penal alemão, de 1962, que substituiu a frase: "A pena não pode ultrapassar a medida da culpabilidade" por uma fórmula incolor: "A culpabilidade do autor é fundamento da medição da pena" porque se aproxima da teoria retributiva e admite dentro de certos limites que, por motivos de prevenção, se agrave a pena que seria adequada à culpabilidade. ${ }^{15}$

A crítica de ROXIN vale para o texto 2, pois só consigna a culpabilidade como um critério de medição de pena, tanto quanto a prevenção.

O texto 1 da Lei de Execução Penal diz que ela "regula o cumprimento da pena e da medida de segurança, a fim de que se alcancem a reprovação e a prevenção do crime".

Já o texto 2 declara que "a execução penal tem por objetivo efetivar as disposições de sentença ou decisão criminal e proporcionar condições para a harmônica integração social do condenado e do internado".

14 ROXIN, Claus. Problemas básicos del derecho penal. Trad. de Diego - Manuel Luzón Peña. Madrid, Reus, 1976, p. 29.

15 id., pp. $29 / 30$. 
A alteração feita é significativa e sem dúvida mais adequada ao estado atual das investigações sobre a pena. Consoante demonstram ROXIN, CALLIESS, BUSTOS RAMIIREZ e até CARNELUTTI, a pena não é um objeto estático, é um processo e no seu dinamismo sobressai ora um ora outro aspecto.

No momento da execução a pena é primacialmente prevenção e prevenção especial, particular, atuando no indivíduo. A reprovação se esgota com a sentença condenatória e a execução é um efeito da reprovação. Não devemos transmudar o efeito em finalidade.

O texto 1 esclarece que constitui “objetivo mediato da execução penal a educação e assistência que, no futuro, facilitem ao condenado harmônica convivência em sociedade". Em outras palavras, o objetivo primário é o cumprimento da pena e da medida de segurança, e o secundário, a ser atingido através do cumprimento das sanções, é a educação e a assistência para facilitar a harmônica convivência do condenado em sociedade.

$\mathrm{O}$ texto 2 não hierarquiza os objetivos ou finalidades que a Exposição de Motivos apresenta da seguinte forma: "a correta efetivação dos mandamentos existentes nas sentenças ou outras decisões, destinado a reprimir e a prevenir os delitos, e a oferta de meios pelos quais os apenados e os submetidos às medidas de segurança venham a ter participação construtiva na comunhão social". ${ }^{16}$

Nota-se que o legislador evitou as palavras readaptação, reinserção, pessocialização, reeducação que, comumente têm sido consideradas como alvos da pena e da execução penal.

O Professor RENÉ DOTTI, um dos integrantes das comissões que elaboraram o Projeto de Reforma Penal, ao analisar os princípios fundamentais da reforma ao tempo em que havia sido publicado o texto 1 , explica o porquê dessa conduta, justificando que aquelas expressões são proclamações otimistas, ideais. ${ }^{17}$ ?

Por sua vez, o Professor MIGUEL REALE JR., também integrante daquelas comissões, explica que foi adotada uma postura realista que percebe os riscos da adoção descuidada da ilusão do tratamento modificador da pessoa do condenado. Reporta-se a Michel Foucault, para quem "a Justiça Penal liberta-se da má consciência de estar punindo, com a escusa de visar à cura, acolhendo modernas técnicas que não mais atuam sobre o corpo mas sobre a alma do condenado, buscando moldar-lhe a personalidade, segundo determinados padrões, muitas vezes politicamente comprometidos". ${ }^{18}$

Por isso, para que se respeitem os pressupostos políticos do Estado de Direito, pena é, em primeiro lugar, a justa retribuição pelo fato praticado, segundo a culpabilidade do seu autor e, na execução, oportu-

16 Projetos de Reforma Penal, Ministério da Justiça, Brasília, 1981, p. 233.

17 DOTTI, René. Os Princípios Fundamentais na Reforma da Execução Penal. Revista Jurídica Lemi/Parte Especial, Set/1982, p. 5.

18 REALE JR, Miguel. Novos rumos do sistema criminal. Rio de Janeiro, Forense, $1^{\text {a }}$. ed., 1983 , p. 47. 
nidade para sugerir a suscitar valores, facilitando a resolução de conflitos pessoais do condenado, mas sem a presunção de transformar cientificamente sua personalidade. ${ }^{19}$

Outro jurista da comissão elaboradora dos anteprojetos, Prof. RICARDO ANTUNES ANDREUCCI, preocupou-se em alinhar os fundamentos ideológicos da reforma penal, notadamente daqueles relacionados com as penas.

Em um artigo declara que o sistema de penas do anteprojeto denota a aceitação de uma concepção clássica, em que a pena é na sua essência retribuição (castigo) adequada à culpabilidade do homem sendo esta a censurabilidade decorrente do juízo de exigibilidade de conduta diversa. Diz revogada hoje a euforia do positivismo e da defesa social porque a idéia de reeducação, levada a seu extremo lógico termina por sujeitar o condenado ao arb ítrio do Estado totalitário. ${ }^{20}$

De qualquer forma, a utilização da expressão "proporcionar condições para a harmônica integração social do condenado e do internado", não impede que se identifique no texto uma concepção prevalentemente preventiva da execução penal, ainda quando a Exposição, interpretando-a, mencione a finalidade de reprimir os delitos.

Reprimir tem muitos sentidos e, entre eles o de conter, refrear, impedir mediante ameaça de castigo, portanto sentido equivalente à intimidação e o de castigar, punir, equivalente à retribuição.

No caso, o sentido só pode ser o de intimidar, realizando tanto a prevenção geral como a especial, pois, como já dito, a reprovação na execução é apenas um efeito, não uma finalidade.

Sob outro ângulo, parece-me que facilitar ao condenado harmônica convivência com a sociedade traduz o mesmo ideal colimado por aqueles que empregam as expressões criticadas pelo Prof. Dotti.

Isso explica o lapso em que incorreu o Expositor ao afirmar que "as penas e medida de segurança devem realizar a proteção dos bens jurídicos e a reincorporação do autor à comunidade." 21

Ora, reincorporação nada mais é do que ressocialização, reintegração, readaptação, reinserção ou reeducação. Podemos traçar distinções entre essas palavras, mas no fundo todas elas querem dizer que o Estado deseja que o indivíduo aceite as regras estabelecidas, não se insurja contra elas. É reincorporação do ponto de vista dos valores adotados pela ideologia dominante.

Por isso me surpreende a afirmação de RENÉ DOTTI de que a Refoma procurou "superar as concepções extremadas e as antinomias que adensam o perfil carismático da pena segregadora ou da pena ressocializadora . . . $\|^{22} \mathrm{E}$ não me convence quando conclui que a superação foi obtida através da concepção da pena com um processo de diálogo entre

19 id., pp. $47 / 48$.

20 ANDREUCCI, Ricardo A., Fundamentos da Reforma Penal; IN Anais do Conselho Nacional de Política Penitenciária, Min. da Justiça, ano I, 1980-81, pp. 175/179.

21 Projetos, p. 233

22 op. cit., p. 4 
o homem, a comunidade e o Estado ${ }^{23}$, pois ainda que se aceite a existência desse diálogo, ele deve versar sobre algum assunto, ponto que permanece obscuro.

Sem dúvida a regra do art. $4^{\circ}$. dos textos 1 e 2 é fruto dessa concepção, que se me afigura mais poética do que real e de todo modo um enfoque tão só descritivo do fenômeno da pena e não explicativo.

A concepção do diálogo é incompatível com a corrente da pena meramente segregadora, mas não o é com a corrente ressocializadora, da qual procura expungir as tendências de massificação e arbitrariedade. Caracteriza-se por uma postura democrática, pluralista, que, todavia, é facilmente olvidada nos programas de readaptação ou naqueles denominados tendentes a proporcionar condições para a harmônica integração social do condenado e do internado.

Em suma, o problema das relações entre o Estado e o indivíduo condenado permanece.

\section{CONCLUSÕES}

Em conclusão verificamos que tecnicamente a Reforma Penal elaborada legislativamente representa um avanço e incorpora idéias desenvolvidas pela doutrina alemã.

Mas, não há nenhuma ruptura com o sistema vigente.

Na vigência do texto primitivo do Código Penal de 1940 a pena era retributiva e preventiva (intimidante), não havendo preocupação com a ressocialização na fase de execução da pena. A Exposição de Motivos inclusive explicita que as penas têm finalidade repressiva e intimidante.

Observe-se que o Código Penal de 1940 conciliou teoricamente duas perspectivas diversas. De um lado os adeptos do classicismo pela concepção da pena retributiva fundada na responsabilidade moral, independente de qualquer finalidade. De outro, os adeptos da Escola Positiva, ao prever a aplicação de medida de segurança ao agente reputado perigoso, seja imputável ou inimputável, esta então com finalidade de readaptação social.

A ruptura desse sistema ideológico adveio com a Lei no. 3.274, de 2 de outubro de 1957, que, pela primeira vez, dispondo sobre a execução das penas, acabou com as distinções entre finalidades diversas destas e das medidas de segurança.

Isso está evidenciado nas seguintes expressões: "tratamento penitenciário adequado" (art. 10., I), "objetivo corretivo e educacional" (art. 10., IV), "tratamento corretivo e educacional" (art. 30.), "toda a educação ... objetivará readaptá-los ao meio social" (art. 20.), "meios de prevenção contra a reincidência" (art. 27).

Posteriormente a Lei no. 6.416, de 24 de maio de 1977, introdu- 
ziu outras importantes modificações ao colocar a periculosidade como centro do sistema de penas e ao criar, em função da periculosidade, a distinção entre regimes penitenciários fechado, semi-aberto e aberto, estes últimos a prenunciar a atual tendência de reservar a prisão aos autores de crimes praticados com violência contra a pessoa.

Com a afirmativa de que não há ruptura do sistema ideológico não quero, entretanto, diminuir o valor das modificações propostas. Assim, a importância conferida à culpabilidade, a adoção dos princípios da subsidiariedade e da efetividade e a formulação de um sistema de penas alternativo à tradicional pena privativa são progressos louváveis.

Mas, me parece que a Reforma Penal situa-se nos lindes de uma simples sistematização da legislação vigente, que, no dizer de REALE "perde-se em casuísmos, misto de lei penal e de execução penal distitu ído de linha mestra" ${ }^{24}$ e de incorporação das interpretações consagradas pelo Judiciário.

Não se trata de reforma de base apta a proporcionar modificação da realidade.

Comentando sobre esta indagação MIGUEL REALE JR. escreve que a realidade não se transforma por meio de textos legais, a lei traduz uma nova diretriz, fixa valores e comportamentos que entende positivos. Sua eficácia depende de uma mudança de mentalidade dos partícipes da Justiça Criminal. ${ }^{25}$

No entanto, como esperar uma mudança de mentalidade se a concepção da pena no tocante a seus fins permanece a mesma? se as contradições imanentes ao ecletismo permanecem? se não houve opção definida quanto à finalidade da pena? É a própria Exposição de Motivos da Lei de Execução Penal que reconhece não terem seus elaboradores questionado profundamente a grande temática das finalidades da pena. ${ }^{26}$

De certo já consciente de críticas dessa ordem, o Prof. ASSIS TOLEDO se apressou em refutá-las declarando recentemente que a refoma não é apenas modificatória, mas estrutural. ${ }^{27}$

Insisto, porém, que a reforma é conjuntural e não estrutural e não acredito que a criminalidade e a violência sofram decréscimo ou que melhore o sistema de execução penal.

Isto porque as modificações propostas se fundamentam em teorias desenvolvidas nos países europeus, especialmente na Alemanha. Ora, essas teorias estão vinculadas a um modelo de Estado determinado. Como lembra MIR PUIG, a teoria da pena e do delito é relativa, não pode ter a pretensão de validade objetiva, pois está condicionada à premissa valorativa de um modelo de Estado determinado.

No caso brasileiro, como de costume, ocorre um transplante das

24 REALE JR, Miguel. ob. cit., p. 39

25.id., p. 89

26 Projetos, p. 233

27. Palestra... 
idéias que não são compatíveis com o nosso modelo político, autoritário e carecedor de legitimidade.

Para que neste País ocorram mudanças é preciso coragem para mergulhar na crise das opções fundamentais, a começar pela discussão ampla sobre as relações entre Estado e indivíduo, os fins e limites da atividade estatal, enfim sobre um novo modelo político consentâneo com as aspirações nacionais.

O problema da pena é político. Dir-se-á de política criminal. Mas, o objeto da política criminal não se circunscreve à proteção jurídicopenal da sociedade. Abrange a criação e a transformação das normas jurídicas, as estruturas oficiais de controle social (polícia, ministério público, tribunais, sistema de execução penal e as situações objetivas de necessidade (pobreza, desemprego) e os fenômenos de discriminação (opinião pública sobre a delinqüência).

Ora, a reforma penal do Governo se reduziu à criação e transformação das normas. Tudo o mais permanece intocado. 